\title{
Prevalence of Relapse of Alcohol Use Disorder and the Association With Self-Efficacy and Perceived Social Support in Butabika Hospital
}

Kenneth Kalani ( $\sim$ okwarekk@gmail.com )

Ministry of Health

Janet Nakigudde

Makerere University

Caroline Birungi

Makerere University

Joy Gumikiriza- Onoria

Makerere University

Nelson Mukiza

King Ceaser University

Anita Arinda

Mildmay Uganda

Betijuma Luwedde

Gulu University

Hillary Irimaso

Kampala Medical Chambers

\section{Research Article}

Keywords: Alcohol use disorder, Relapse, Self-efficacy, Perceived social support

Posted Date: May 19th, 2021

DOI: https://doi.org/10.21203/rs.3.rs-515362/v1

License: (c) (1) This work is licensed under a Creative Commons Attribution 4.0 International License. Read Full License 


\section{Abstract \\ Background}

Alcohol use disorder (AUD) is a problem globally and Uganda has one of the highest per capita alcohol consumption rates in sub-Saharan Africa. Relapse is a distressing aspect in the treatment of AUD and it is mediated by self-efficacy and perceived social support besides other psychosocial factors. In Uganda, there is paucity of data regarding relapse of AUD and the association with self-efficacy and perceived social support hence the need to carry out this study.

\section{Objective}

To determine the prevalence of relapse of AUD and the association with self-efficacy and perceived social support at Butabika hospital.

\section{Methods}

A cross-sectional study design was used and 269 participants that received treatment for AUD at hospital in the period between 1 st /01/2016 and 31st /12/2017 were consecutively recruited. Participants were assessed for relapse of AUD using the SCID- 5 substance use disorder section. Data was collected using a socio-demographic questionnaire, the general self-efficacy scale and the multidimensional scale for perceived social support. Data was entered in Epidata 3.0 and imported into STATA version 14 for analysis. Chi square test and logistic regression were used at bi-variable and multivariable analysis respectively to determine associations.

\section{Results}

The prevalence of relapse of AUD among the 269 participants was $63.3 \%$ (170). Of those who relapsed, $98 \%$ (167) had severe AUD. Participants with a marital status of single were less likely to relapse into alcohol use than those with a marital status of; separated or divorced $(\mathrm{OR}=6.81 ; 95 \% \mathrm{Cl}=1.53-30.32$; $\mathrm{p}$ value $=0.012)$ and married $(\mathrm{OR}=2.86 ; 95 \% \mathrm{Cl}=1.07-7.65 ; \mathrm{p}$-value $=0.037)$. Male participants were more likely to relapse into AUD than the females $(O R=0.19 ; 95 \% \mathrm{Cl}=0.04-0.86 ; \mathrm{p}$-value $=0.03)$. Participants with higher perceived social support $(\mathrm{OR}=0.85 ; 95 \% \mathrm{Cl}=0.81-0.9 ; \mathrm{p}$-value $=<0.001)$ were less likely to relapse into AUD. Self-efficacy $(\mathrm{OR}=0.93 ; 95 \% \mathrm{Cl}=0.85-1$; $\mathrm{p}$-value $=0.061)$ was not significantly associated with relapse of AUD.

\section{Conclusion}


The prevalence of relapse of AUD is high and is associated with perceived social support, marital status of; separated, divorced or married, and female gender. Relapse prevention programs should emphasize the importance of social support in the management of patients with AUD. Further research to assess the relationship between relapse of AUD among married people is recommended.

\section{Introduction}

Alcohol use disorder (AUD) is characterized by numerous problems among which is tolerance, craving, withdrawal, using larger amounts of alcohol than intended; much time spent using alcohol, neglecting major roles in preference to alcohol, interpersonal problems and hazardous use (1). AUD is associated with adverse physical and mental health consequences that include; many serious social issues, violence, child neglect and abuse, and absenteeism in the workplace (2). Alcohol is a causal factor in 60 types of diseases and injuries and a component cause in 200 others (2). It accounts for $4 \%$ of the global burden of disease (3).

The Global status report on alcohol and health in 2014, placed Uganda's pure alcohol per capita consumption at 9.8 litres, which is above the African average of 6.2 litres and among the highest globally (2). Furthermore, Uganda has been posted as one of the countries with the largest percentage of people with AUDs in the world with 5.8 percent of her total population being diagnosed with AUD (2). More recently, a Ugandan based study estimated the country's prevalence of AUD to be at $9.8 \%$ (4).

One of the most distressing aspects in the management of AUD is relapse, which is mediated by several biological and psychosocial factors. Factors that have been associated with relapse among persons with AUD and other substance use disorders include; negative social support, lack of self-efficacy, stigma, shame and denial among others $(5,6)$. Psychosocial variables such as self-efficacy and perceived social support have been identified as major contributors of relapse of AUD (7) A change in self-efficacy over the course of treatment seems to reflect a patient future success in achieving long-term abstinence (8). Social support has also been found to have a positive effect on alcohol sobriety through enhancing effective coping strategies (9).

Research on the psychosocial factors associated with relapse of alcohol-related disorders in Uganda is lacking (10). Given the paucity of research, the current study sought to estimate the prevalence of relapse of alcohol use disorder and the association with self-efficacy and social support at Butabika Hospital, Uganda. In so doing, an understanding of the psychosocial factors associated with relapse of AUD may help improve care in this class of patients in Sub-Saharan Africa and subsequently reduce the frequency of relapses.

\section{Methods}

\section{Study Design and setting}


This study used a descriptive cross-sectional study design. The study was conducted at Butabika national referral and teaching hospital. Butabika hospital is located about $10 \mathrm{~km}$ East of Kampala City and it is the second biggest hospital in Uganda with a bed capacity of 550. Butabika hospital was established in 1955, and it is the only specialized Mental Health Institution in Uganda. In addition to the provision of mental health services, Butabika hospital is also a teaching center to various professionals undertaking mental health as part of their course. Butabika hospital has the Alcohol and Drug Unit (ADU) which is a 32-bed capacity unit specifically to manage patients with alcohol and other substance use disorders. The ADU runs a clinic every Tuesday and Thursday where averagely twenty patients are seen per clinic day. In 2017, a total of 574 patients (both in- patients and out-patients) attended the ADU. The ADU often does not have the capacity to admit all the patients with alcohol use disorders visiting the hospital. These patients are often admitted in the other wards and only transferred to ADU when some discharges have been made. The average bed stay in the ADU is twelve weeks.

\section{Study participants}

Participants above 18 years that received treatment for AUD in the period between 1st / January/2016 and 31st /December/2017 at Butabika hospital and consented were included in the study. Participants that had co-morbid severe mental illness and those that fullfilled the DSM-5 criteria for another substance use disorder were excluded from the study.

\section{Data collection tools}

A socio-demographic questionnaire was used to record the social demographic characteristics and clinical data related to alcohol use. The social demographic variables included age, sex, address, gender, religion, current employment, marital status, education level and current employment status.

Self efficacy will be measured using generalized self efficacy scale (GSE) (7).

The GSE is a 10-item unidimensional scale designed to assess optimistic self-beliefs used to cope with a variety of demands in life. The scale was designed to assess self efficacy. The scaled score for each question ranges from 1 to 4 .The total score ranges between 10 and 40 , with a higher score indicating more self-efficacy. The scale was originally developed by Jerusalemand Schwarzer in 1981 in Germany and has been translated into many languages. Studies have shown that the GSE has high reliability, stability, and construct validity $(11,12)$. The scale was found to be configurally equivalent across 28 nations, and it forms only one global dimension $(11,13)$. Cronbach alpha ranges from 0.75 to 0.94 across a number of different language versions $(8,14)$. Relations between the GSE and other social cognitive variables (intention, implementation of intentions, outcome expectations, and self-regulation) are high and confirm the validity of the scale (8).

Multidimensional Scale of Perceived Social Support - (MSPSS) $(15,16)$ was used to measure perceived social support. The tool was validated and adapted for the Ugandan setting and was found to have good psychometric properties with Cronbach alpha values $0.79,0.80$, and 0.82 on all 3 sub scales (Family, Friends and Significant other respectively) and internal consistency of 0.83 (15). The MSPSS is a brief 
self-report questionnaire with 12 items that subjectively measure perceived social support. Each of the three subscales has four items with 5 point Likert scale with response codes as $1=$ Strongly Disagree, $2=$ Mildly Disagree, 3 = Neutral, 4 = Mildly Agree and 5 = Strongly Agree.

\section{Study Procedure}

A list of 606 names of patients with a diagnosis of AUD who attended the ADU in the period between 01st / January/ 2016 and 31st / December/ 2017 and their corresponding phone contacts was generated from the registry and files. Using this list, 115 potential participants were either admitted or approached in out-patient department during the study period. 409 potential participants were to be called but only 369 files had valid telephone contacts. These were called up and briefed about the study. Of the 369 potential participants contacted, 217 responded and were assessed for eligibility. Amongst the participants that responded on calling, 37 did not meet the inclusion criteria while 180 met the inclusion criteria and were included in the study. Amongst the participants that were found in hospital during the study period, 26 did not meet the inclusion criteria while 89 met the inclusion criteria and were included in the study. The potential participants that used other substance(s) were assessed using SCID-5 non alcohol substance use disorder section to find out if they met the DSM- 5 criteria for another substance use disorder. Those that met the criteria for another substance use disorder were excluded from the study. We explained the study purpose and procedures to the potential participants that met the inclusion criteria and obtained informed consent from them. A total of 269 participants were included in the study. These were assessed for relapse of AUD using the SCID-5 alcohol use disorder section and the other study tools were also be administered. Upon completion, we assessed the participant for any medical or psychiatric needs clinically and addressed them if present. The filled-in questionnaires were labeled with a study number and anonymized. The questionnaires were then locked away in a safe cabinet by the investigator pending data entry. Data was collected over a two-month period, that is, from 24th /December/2018 to 24th /January/2019. A detail of the recruitment process is presented in the flow chart below.

\section{Statistical analysis}

Data was entered into EPI DATA Version 3.0 and then exported to STATA College Station TX Version 14 for data cleaning and analysis. Data analysis was conducted using STATA College Station TX Version 14. Baseline characteristics were analyzed using summary statistics. Continuous variables were expressed as means and their standard deviations for normally distributed data. Skewed data were expressed as medians and their corresponding quartiles. Categorical variables were expressed as frequencies and proportions and displayed in form of tables. To describe the association between relapse of AUD and socio- demographic variables, we used a bivariate analysis using $95 \%$ Confidence intervals. Using backward elimination we determined the model of best fit with inclusion criteria set at $p=0.1$. The Simple logistic regression analysis was used to determine the bi-variable association of categorical variables and relapse of AUD. T-test was used in assessment of measures of association for continuous variables. All variables that were found to be statistically significant at the bi-variable analyses were entered into a hierarchical logistic regression analysis, and used to determine the factors associated with relapse of AUD. The level of significance was set at $5 \%$ 


\section{Results}

\section{Socio-demographic characteristics}

A total of 269 participants aged 18 years and above were included in the study. The mean age of the participants was 37 years with a standard deviation of 10. Most, 251 (93.3\%) of the participants were male. One hundred and fifty-seven (58.4\%) of the participants were single and $71(26.4 \%)$ were married. Almost half, $139(51.7 \%)$ of the participants were catholic. The rest of the socio-demographic characteristics are represented in Table 1 below. 
Table 1

Socio-demographic characteristics of the study participants

\begin{tabular}{|c|c|c|}
\hline Variable & $\begin{array}{l}\text { Frequency } \\
(\mathrm{N}=269)\end{array}$ & Percent (\%) \\
\hline \multicolumn{3}{|l|}{ Gender } \\
\hline Male & 251 & 93.3 \\
\hline Female & 18 & 6.7 \\
\hline \multicolumn{3}{|l|}{ Religion } \\
\hline Protestant & 86 & 32.0 \\
\hline Catholic & 139 & 51.7 \\
\hline Moslem & 30 & 11.2 \\
\hline Others & 14 & 5.2 \\
\hline \multicolumn{3}{|l|}{ Education Status } \\
\hline None & 7 & 2.6 \\
\hline Primary & 20 & 7.4 \\
\hline Secondary & 79 & 29.4 \\
\hline Tertiary & 163 & 60.6 \\
\hline \multicolumn{3}{|l|}{ Marital Status } \\
\hline Single & 157 & 58.4 \\
\hline Married & 71 & 26.4 \\
\hline Separated/divorced & 36 & 13.4 \\
\hline Widowed & 5 & 1.9 \\
\hline \multicolumn{3}{|l|}{ Employment Status } \\
\hline Employed & 133 & 49.4 \\
\hline Unemployed & 114 & 42.4 \\
\hline Student & 22 & 8.2 \\
\hline Number of children (median \pm iqr) & $1 \pm 2$ & \\
\hline Number of people lived with (median \pm iqr) & $4 \pm 3$ & \\
\hline Age in years (Mean $\pm S D$ ) & $37 \pm 10$ & \\
\hline
\end{tabular}




\section{Clinical characteristics}

Amongst all the participants, $63 \%$ (170) met the DSM-5 criteria for relapse of alcohol use disorder. The majority, $62.1 \%$ (167) of the participants had a severe alcohol use disorder. Most, $75 \%$ (204) used other substances that did not meet the DSM- 5 criteria for non-alcohol use disorder. The mean duration of alcohol use was 16 years with a standard deviation of 8 . Details of the clinical characteristics are presented in Table 2 below.

Table 2

Clinical profile of participants

\begin{tabular}{|c|c|c|}
\hline Variable & $\begin{array}{l}\text { Frequency } \\
(\mathrm{N}=269)\end{array}$ & Percentage (\%) \\
\hline \multicolumn{3}{|l|}{ Alcohol use disorder relapse ${ }^{\star}$} \\
\hline No & 99 & 36.8 \\
\hline Yes & 170 & 63.2 \\
\hline \multicolumn{3}{|l|}{ Diagnosis of alcohol use disorder ${ }^{\star}$} \\
\hline Mild & 2 & 0.7 \\
\hline Moderate & 1 & 0.4 \\
\hline Severe & 167 & 62.1 \\
\hline None & 99 & 36.8 \\
\hline \multicolumn{3}{|l|}{ Other substances used ${ }^{\star *}$} \\
\hline No & 204 & 75.8 \\
\hline Yes & 65 & 24.2 \\
\hline Duration of alcohol use (Mean \pm SD) & $16 \pm 8$ & \\
\hline Number of previous admissions(Mean \pm SD) & $3 \pm 5$ & \\
\hline \multicolumn{3}{|c|}{ *Diagnosis made using SCID-5 Alcohol use disorder } \\
\hline \multicolumn{3}{|c|}{ **Other substances used that did not fit the DSM- 5 criteria for another substance use disord } \\
\hline
\end{tabular}

The mean scores of the participants on the GSE scale and the MSPSS scale was 31.1 with a standard deviation of 5.1 and 39.3 with a standard deviation of 10 respectively. 
General self-efficacy and perceived social support were significantly associated with relapse of AUD ( $p<$ 0.001). From the multidimensional scale of perceived social support however, the perceived support from friends was not significantly associated with relapse of AUD $(p=0.686)$. Details of these associations are presented in Table 3.

Table 3

Association of relapse of AUD with self-efficacy and perceived social support

\begin{tabular}{|c|c|c|c|c|}
\hline \multicolumn{5}{|l|}{ AUD Relapse ${ }^{*}$} \\
\hline \multirow[t]{2}{*}{ Variables } & Sample(N = 269) & No(n= 99) & $\operatorname{Yes}(n=170)$ & p-value \\
\hline & $($ Mean \pm SD) & $($ Mean \pm SD $)$ & $($ Mean $\pm S D)$ & \\
\hline General Self-efficacy- scores & $31.1 \pm 5.1$ & $33.2 \pm 4.2$ & $29.9 \pm 5.1$ & $<0.001^{\mathrm{t}}$ \\
\hline MSPSS- total scores & $39.3 \pm 10$ & $46.3 \pm 7.8$ & $35.3 \pm 8.8$ & $<0.001^{t}$ \\
\hline MSPSS-Significant others sub- & $13.7 \pm 4.1$ & $16.5 \pm 3.2$ & $12.1 \pm 3.7$ & $<0.001^{t}$ \\
\hline \multicolumn{5}{|l|}{ Scores } \\
\hline MSPSS-Family sub-scores & $13.1 \pm 5.3$ & $17.5 \pm 3.6$ & $10.6 \pm 4.4$ & $<0.001^{t}$ \\
\hline MSPSS-Friends sub-scores & $12.5 \pm 4.7$ & $12.3 \pm 5$ & $12.6 \pm 4.5$ & $0.686^{t}$ \\
\hline \multicolumn{5}{|c|}{ Note $t=p$-value generated by student- test for mean difference } \\
\hline
\end{tabular}

MSPSS - Multidimensional scale of perceived social support

*Diagnosis made using SCID-5 Alcohol use disorder

\section{Factors Associated with Relapse of AUD at Multi-Variable Logistic Regression}

Participants with a marital status of single were less likely to relapse into alcohol use than those with a marital status of; separated or divorced $(\mathrm{OR}=6.81 ; 95 \% \mathrm{Cl}=1.53-30.32 ; \mathrm{p}$-value $=0.012)$ and married $(\mathrm{OR}=2.86 ; 95 \% \mathrm{Cl}=1.07-7.65 ; \mathrm{p}$-value $=0.037)$. Male participants were more likely to relapse into AUD than the female $(\mathrm{OR}=0.19 ; 95 \% \mathrm{Cl}=0.04-0.86 ; \mathrm{p}$-value $=0.03)$. Participants with a higher perceived social support $(\mathrm{OR}=0.85 ; 95 \% \mathrm{Cl}=0.81-0.9 ; \mathrm{p}$-value $=<0.001)$ were less likely to relapse into AUD. Self-efficacy $(\mathrm{OR}=0.93 ; 95 \% \mathrm{Cl}=0.85-1 ; \mathrm{p}$-value $=0.061)$ was not significantly associated with relapse of AUD. Details of these associations are presented in Table 4. 
Table 4

Multi-variable logistic regression for factors associated with relapse of AUD

\begin{tabular}{|c|c|c|c|c|}
\hline Variable & $\begin{array}{l}\text { Unadjusted OR } \\
(95 \% \mathrm{Cl})\end{array}$ & & $\begin{array}{l}\text { Adjusted OR } \\
(95 \% \mathrm{Cl})\end{array}$ & p-value \\
\hline Self-efficacy total score & $0.86(0.81,0.91)$ & $<0.001$ & $0.93(0.85,1)$ & 0.061 \\
\hline MSPSS Total score & $0.85(0.82,0.89)$ & $<0.001$ & $0.85(0.81,0.9)$ & $<0.001$ \\
\hline Previous admissions & $1.08(0.97,1.19)$ & 0.159 & $1.02(0.95,1.09)$ & 0.596 \\
\hline Age in years & $1.07(1.04,1.11)$ & $<0.001$ & $0.96(0.9,1.02)$ & 0.183 \\
\hline Duration of alcohol use & $3.24(2.28,4.6)$ & $<0.001$ & $1.79(0.89,3.59)$ & 0.102 \\
\hline \multicolumn{5}{|l|}{ Gender } \\
\hline Male & 1 & & 1 & \\
\hline Female & $0.27(0.1,0.73)$ & 0.01 & $0.19(0.04,0.86)$ & 0.03 \\
\hline \multicolumn{5}{|l|}{ Marital Status } \\
\hline Single & 1 & & 1 & \\
\hline Married & $2.5(1.36,4.61)$ & 0.003 & $2.86(1.07,7.65)$ & 0.037 \\
\hline Separated/divorced & $7.32(2.47,21.67)$ & $<0.001$ & $6.81(1.53,30.32)$ & 0.012 \\
\hline Widowed & $3.66(0.4,33.47)$ & 0.251 & $1.47(0.1,20.66)$ & 0.775 \\
\hline \multicolumn{5}{|l|}{ Religion } \\
\hline Protestant & 1 & & 1 & \\
\hline Catholic & $1.89(1.08,3.31)$ & 0.026 & $1.95(0.86,4.43)$ & 0.109 \\
\hline Moslem & $1.37(0.58,3.22)$ & 0.474 & $1.62(0.38,6.99)$ & 0.518 \\
\hline Others & $0.44(0.14,1.42)$ & 0.17 & $0.47(0.08,2.62)$ & 0.385 \\
\hline \multicolumn{5}{|l|}{ Employment status } \\
\hline Employed & & & 1 & \\
\hline Unemployed & $0.8(0.47,1.36)$ & 0.402 & $1(0.47,2.16)$ & 0.993 \\
\hline Student & $0.07(0.02,0.24)$ & $<0.001$ & $0.14(0.23,0.67)$ & 0.14 \\
\hline \multicolumn{5}{|l|}{ Other substance ${ }^{\star \star}$} \\
\hline No & 1 & & 1 & \\
\hline
\end{tabular}

**Other substances used that do not fit the DSM- 5 criteria for another substance use disorder MSPSS

- Multidimensional scale of perceived social support 


\begin{tabular}{|c|c|c|c|c|}
\hline Variable & $\begin{array}{l}\text { Unadjusted OR } \\
(95 \% \mathrm{Cl})\end{array}$ & & $\begin{array}{l}\text { Adjusted OR } \\
(95 \% \mathrm{Cl})\end{array}$ & p-value \\
\hline Yes & $0.36(0.20,0.64)$ & $<0.001$ & $0.45(0.19,1.06)$ & 0.067 \\
\hline
\end{tabular}

\section{Discussion}

\section{Prevalence of Relapse of AUD}

This study set out to determine the prevalence of relapse of alcohol use disorder at Butabika hospital. It was found a high prevalence of relapse of AUD at $63 \%$. This finding is comparable to a study that found a relapse rate of $66.6 \%$ in participants with AUD in a three year period after treatment (17). Other studies have found comparable relapse rates of alcohol dependence after initial treatment $(18,19)$. This prevalence would have been even higher given that we excluded all persons with other co-morbid substance use disorders.

This prevalence was higher compared to a study in Kenya that found a prevalence of relapse of alcohol use disorder at $43 \%$ (20). The difference could be due to the fact that their study population consisted of participants who were admitted in one of the four selected rehabilitation centers at the time of the study and yet in the current study, we called back participants for assessments after they were treated for AUD and discharged. The Kenyan study therefore could have left out persons who relapsed but were not admitted in a rehabilitation center. Another reason for the difference in the prevalence of relapse of AUD could have resulted from the differences in sample size. They used a smaller sample size of 100 participants whereas the current study used a sample size of 269 participants.

Another study in Kenya found a relapse rate of alcohol dependence at $43.1 \%$ (21). This finding was less than that of the current study possibly due to the difference in the period of assessment following treatment. In the current study, participants were assessed for relapse of AUD at least after a one-year period following treatment whereas Kuria assessed all her participants for relapse after a six-month period. If assessed after a longer period, perhaps many more of her participants may have relapsed.

\section{The Association of Relapse of Alcohol Use Disorder with Self-Efficacy and Perceived Social Support.}

Gender was significantly associated with relapse of AUD. The female gender was less likely to relapse as compared to the male. This finding is consistent with other studies $(9,17,22,23)$. 
Possible explanations for the gender difference could be that; women are generally lighter drinkers of alcohol than men are; drinking alcohol is not as important to women's social roles as it is to men's; and/or women who cease drinking alcohol during pregnancy and early childrearing may then not resume drinking later on (24). Our study did not find significant association between relapse of AUD and age, duration of alcohol use and number of previous relapses.

Marital status of separated or divorced was significantly associated with relapse of AUD. The finding that persons with a marital status of separated or divorced are more likely to relapse is consistent with other studies in this field $(17,23,25)$.

This study found that those who are married were more likely to relapse into alcohol use. This was an unexpected finding and is contrary to several studies that have found that being married is protective against relapse of alcohol use $(17,23,26,27)$. Unresolved and ongoing marital distress that was associated with the initial alcohol use problems could explain this finding.

Perceived social support was generally found to be lower among participants that had relapsed. This finding is consistent with, and adds to previous research in this area which has demonstrated that higher perceived social support is associated with maintenance of sobriety in persons treated for alcohol use disorders (28-30). Further analysis of the perceived social support showed that participants with higher perceived social support from family and significant others was less likely to relapse. Perceived social support from friends was however not associated with relapse of AUD in the current study. This is probably because all the participants felt that they had some sort of social support from their friends.

Several studies that investigated the association between relapse of AUD and self-efficacy have had mixed findings. Some studies show that people with a higher self-efficacy are less likely to relapse into alcohol dependence $(9,22,25,30)$ whereas others find no significant association between relapse of alcohol use disorder and self-efficacy $(7,31)$. Our study did not find a significant association between relapse of AUD and self-efficacy. This could be because all participants had a perception of self-efficacy but those that relapsed probably had misperceived feelings of control over use of alcohol. The participants in this study appeared to be cognizant of their abilities as reflected by the congruence in their actions (to use or not to use alcohol).

\section{Study Limitations}

This being a cross-sectional study, temporal relationships between relapse of AUD and the associated factors could not be established. Furthermore, inferences about causation of relapse could not be ascertained because the exposure and outcome were measured the same time. However, considering that we aimed to determine the prevalence and associated factors of relapse of alcohol use disorder, a cross sectional study design was the most appropriate.

The target sample size to infer prevalence in this study was not reached because many potential participants either did not have valid telephone contacts or did not respond despite several attempts to call them. The sample size was however adequate to determine associations in the study. 
No objective tests such as urine or blood analysis for alcohol were used to confirm abstinence or recent alcohol use.

\section{Conclusion}

The prevalence of relapse of AUD is high and is associated with perceived social support, a marital status of; married, separated or divorced and female gender.

Relapse prevention programs at health facilities should emphasize social support from family members and significant others and patients with a marital status of divorced or separated should be managed more robustly.

Further research studies should be carried out to assess the relationship between relapse of AUD and being married.

\section{List Of Abbreviations}

AUD: Alcohol Use Disorder

DSM-5: Diagnostic statistical manual - fifth edition ADU: Alcohol and Drug Unit

SCID-5: Structured clinical interview for DSM-5

MSPSS: Multidimensional scale of perceived social support

GSE: General Self-efficacy

\section{Declarations}

\section{Ethics approval and consent to participate}

Ethical approval was sought from Makerere University School of Medicine Research Ethics Committee (SOMREC) and administrative clearance was obtained from Butabika Hospital. All methods were performed in accordance with the relevant guidelines and regulations. Written informed consent was obtained from persons taking part in the study. For illiterate participants, informed consent was obtained from their legally authorized representatives.

\section{Consent for publication:}

Not applicable

\section{Availability of data and materials:}


The datasets used and/or analysed during the current study are available from the corresponding author on reasonable request.

\section{Competing interests:}

The authors declare that they have no competing interests

\section{Funding:}

The study was made possible by a scholarship fund awarded to KK by the Department of Psychiatry of Makerere University under the African Psychcare Research scholarships grant. The funding body did not have any role in the design of the study and collection, analysis, and interpretation of data and in writing the manuscript.

\section{Authors' contributions:}

KK conceptualized and designed the study, collected the data and wrote the paper. JN, CB, NM, AA, HI and $\mathrm{BL}$ conceptualized and supervised the study and helped in editing the paper. All authors have read and approved the final manuscript.

\section{Acknowledgements:}

Not applicable

\section{References}

1. American Psychiatric Association. Diagnostic and statistical manual of mental disorders (DSM-5®): American Psychiatric Pub; 2013.

2. World Health Organization. Global status report on alcohol and health-2014: World Health Organization; 2014.

3. Obot IS, Room R. Alcohol, gender and drinking problems: perspectives from low and middle income countries: World Health Organization; 2005.

4. Kabwama SN, Ndyanabangi S, Mutungi G, Wesonga R, Bahendeka SK, Guwatudde D. Alcohol use among adults in Uganda: findings from the countrywide non-communicable diseases risk factor cross-sectional survey. Global health action. 2016;9(1):31302.

5. Wallhed Finn S, Bakshi A-S, Andréasson S. Alcohol consumption, dependence, and treatment barriers: perceptions among nontreatment seekers with alcohol dependence. Substance Use \& Misuse. 2014;49(6):762-9.

6. Pasche S, Kleintjes S, Wilson D, Stein DJ, Myers B. Improving addiction care in South Africa: Development and challenges to implementing training in addictions care at the University of Cape Town. International Journal of Mental Health and Addiction. 2015;13(3):322-32. 
7. D Al Abeiat D, M Hamdan-Mansour A, I Hanouneh S, M Ghannam B. Psychosocial predictors of relapse among patients with alcohol problems. Current drug abuse reviews. 2016;9(1):19-25.

8. Luszczynska A, Scholz U, Schwarzer R. The general self-efficacy scale: multicultural validation studies. The Journal of psychology. 2005;139(5):439-57.

9. Mattoo S, Chakrabarti S, Anjaiah M. Psychosocial factors associated with relapse in men with alcohol or opioid dependence. 2009.

10. Kalema D, Vanderplasschen W. Features and challenges of alcohol abuse treatment in Uganda. African Journal of Drug and Alcohol Studies. 2015;14(2):125-35.

11. Leganger A, Kraft P, Rysamb E. Perceived self-efficacy in health behaviour research: Conceptualisation, measurement and correlates. Psychology and Health. 2000;15(1):51-69.

12. Schwarzer R, Mueller J, Greenglass E. Assessment of perceived general self-efficacy on the Internet: Data collection in cyberspace. Anxiety, stress and coping. 1999;12(2):145-61.

13. Scholz U, Doña BG, Sud S, Schwarzer R. Is general self-efficacy a universal construct? Psychometric findings from 25 countries. European journal of psychological assessment. 2002;18(3):242.

14. Rimm H, Jerusalem M. Adaptation and validation of an Estonian version of the General Self-Efficacy Scale (ESES). Anxiety, Stress, and Coping. 1999;12(3):329-45.

15. Nakigudde J, Musisi S, Ehnvall A, Airaksinen E, Agren H. Adaptation of the multidimensional scale of perceived social support in a Ugandan setting. African health sciences. 2009;9(2).

16. Zimet GD, Dahlem NW, Zimet SG, Farley GK. The multidimensional scale of perceived social support. Journal of personality assessment. 1988;52(1):30-41.

17. Moos RH, Moos BS. Rates and predictors of relapse after natural and treated remission from alcohol use disorders. Addiction. 2006;101(2):212-22.

18. Finney JW, Moos RH, Timko C. The course of treated and untreated substance use disorders: Remission and resolution, relapse and mortality. Addictions: A comprehensive guidebook. 1999:3049.

19. Jin H, Rourke SB, Patterson TL, Taylor MJ, Grant I. Predictors of relapse in long-term abstinent alcoholics. Journal of Studies on Alcohol. 1998;59(6):640-6.

20. Chepkwony SJ, Chelule E, Barmao AC. An Investigation Into Prevalence And Factors Contributing To Relapse Among Alcoholics In Selected Rehabilitation Centres In Nairobi County, Kenya. International Journal of Innovative Research and Development. 2013;2(8).

21. Kuria MW. Factors associated with relapse and remission of alcohol dependent persons after community based treatment. Open Journal of Psychiatry. 2013;3(02):264.

22. Kumar A, Srinivas K, Muralidhara K. Assessment of relationship of psychosocial factors contributing to relapse and maintenance of abstinence in patients undergoing alcohol de-addiction therapy in KIMS, Hubli-A Longitudinal survey. GLOBAL JOURNAL FOR RESEARCH ANALYSIS. 2018;6(3).

23. Ornstein P, Cherepon JA. Demographic variables as predictors of alcoholism treatment outcome. Journal of Studies on Alcohol. 1985;46(5):425-32. 
24. Wilsnack RW, Wilsnack SC, Kristjanson AF, Vogeltanz-Holm ND, Gmel G. Gender and alcohol consumption: patterns from the multinational GENACIS project. Addiction. 2009;104(9):1487-500.

25. Kaundal PK, Sharma I, Jha T. Assessment of psychosocial factors associated with relapse in patients with alcohol dependence: a retrospective observational study. International Journal of Basic \& Clinical Pharmacology. 2016;5(3):969-74.

26. Afsar A, Bashirian S, Poorolaja J, Hazavehei S, Vatan Nawaz E, Zinat Motlagh F. Predictive factors of relapse among patients treated with methadone maintenance treatment referred to addiction centers in Hamadan based on health belief model. J Health Syst Res. 2014;9(14):2034-45.

27. Lin C, Wu Z, Detels R. Family support, quality of life and concurrent substance use among methadone maintenance therapy clients in China. Public health. 2011;125(5):269-74.

28. Dobkin PL, Civita MD, Paraherakis A, Gill K. The role of functional social support in treatment retention and outcomes among outpatient adult substance abusers. Addiction. 2002;97(3):347-56.

29. Gordon AJ, Zrull M. Social networks and recovery: One year after inpatient treatment. Journal of Substance Abuse Treatment. 1991;8(3):143-52.

30. Kamal P, Ravi S, Dinesh D, Sharma. Evaluation Of Various Psychosocial And Clinical Factors Associated With Relapse In Patients With Alcohol Dependence At A Tertiary Care Hospital:Observational Study. Indian Journal of Basic and Applied Medical Research. 2017;6(3):37584.

31. Dolan SL, Martin RA, Rohsenow DJ. Self-efficacy for cocaine abstinence: Pretreatment correlates and relationship to outcomes. Addictive behaviors. 2008;33(5):675-88. 